\title{
Effect of Knee Brace Type on Braking Response Time During Automobile Driving
}

\author{
PhD - Thesis
}

Dr. med. univ. Dietmar DAMMERER

Department of Orthopaedic Surgery

Medical University of Innsbruck, Austria, Europe

\author{
Thesis Committee \\ Supervisor: Priv. Doz. Mag. Dr. Michael C. Liebensteiner, $\mathrm{PhD}^{1}$ \\ $1^{\text {st }}$ Member: Univ. - Prof. Dr. Martin Krismer ${ }^{1}$ \\ $2^{\text {nd }}$ Member: Univ. - Prof. Dr. Eckart Mayr ${ }^{2}$ \\ ${ }^{1}$ Department of Orthopaedic Surgery, Medical University of Innsbruck, Austria \\ ${ }^{2}$ Department of Orthopaedic Surgery, AKH Celle, Germany
}

Published online in: „Arthroscopy - The Journal of Arthroscopic and Related Surgery“ Vol 31, No 3 (March), 2015: pp 404-409

Department of Orthopaedic Surgery; Medical University of Innsbruck, Austria 


\section{Table of Contents}

1. Abstract.................................................................. 4

2. Introduction....................................................... 6

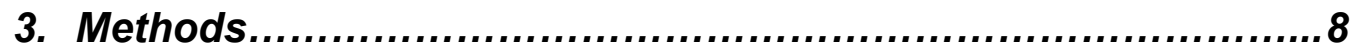

4. Results............................................................. 11

5. Discussion................................................................. 12

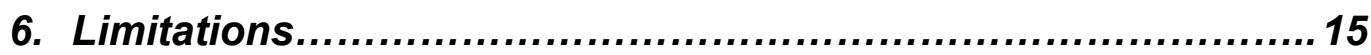

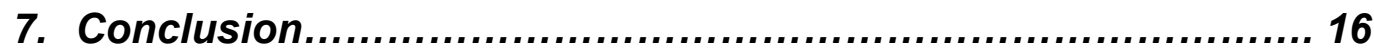

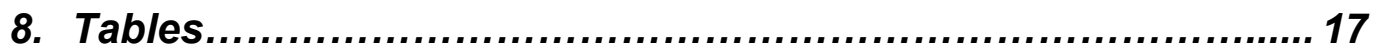

9. Figures.............................................................. 19

10. Competing interests.............................................. 21

11. References............................................................. 22

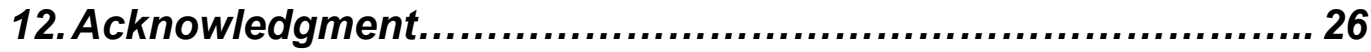

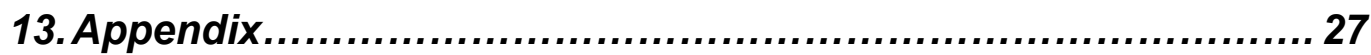

13.1. Case Report Form ......................................... 27

13.2. Ethics committee approval..................................... 28

13.3. AGES committee approval........................................29

13.4. Abstracts and Publication....................................... 31

13.5. Poster Presentation................................................ 32

13.6. Further scientific work........................................ 33

13.6.1. Original research publications............................ 33

13.6.2. Abstracts - Oral Presentations............................ 34

PhD - Thesis 2

Department of Orthopaedic Surgery; Medical University of Innsbruck, Austria 
13.6.3. Poster presentation...................................... 35

13.6.4. Submitted Manuscripts................................... 36

14. Declaration of Originality ........................................ 37

15. Published Article.......................................................... 38 


\section{Abstract}

\section{Purpose:}

To assess driving ability (brake response time [BRT]) with commonly used knee braces.

\section{Methods:}

Sixty-four healthy participants (32 women and 32 men) participated in our study. BRT was assessed using a custom-made driving simulator. We assessed BRT for 5 different commonly used knee braces (right leg) used in 9 different settings: without a knee brace (control group); with a typical postoperative knee brace with adjustable range of motion (ROM) and the settings of $0^{\circ}$ to $30^{\circ}, 0^{\circ}$ to $60^{\circ}, 0^{\circ}$ to $90^{\circ}$, and $20^{\circ}$ to $90^{\circ}$ (extension and flexion); and with an unloading knee brace for moderate to severe unicompartmental osteoarthritis, an orthosis for ligament instabilities, a knee brace for patellofemoral disorders, and an elastic knee bandage.

Results: The 64 participants (mean age, 33.5 years) showed significantly impaired BRT with the typical postoperative brace set at an ROM of $0^{\circ}$ to $30^{\circ}(673$ milliseconds, $\mathrm{P}<$ $.001)$, ROM of $0^{\circ}$ to $60^{\circ}$ (629 milliseconds, $\left.\mathrm{P}<.001\right)$, ROM of $0^{\circ}$ to $90^{\circ}(607$ milliseconds, $\mathrm{P}=.001)$, and $\mathrm{ROM}$ of $20^{\circ}$ to $90^{\circ}(602$ milliseconds, $\mathrm{P}=.005)$ compared with the control group. However, no such impaired BRT was found for any other investigated knee brace. 
Conclusions: Right-sided ROM-restricting knee braces involve significant impairment of BRT in healthy participants. No such prolonged BRT was found for a patellofemoral realignment brace, a ligament brace, a valgus/osteoarthritis brace, or an elastic knee bandage. However, our findings should be viewed in light of the limitations of the study, which are (1) the lack of a defined decrease in BRT that could lead to an accident and (2) uncertainty of whether the statistical differences are also clinically important.

Level of Evidence: Level II, lesser-quality randomized controlled trial.

\section{Key Words:}

Brake Response Time, Driving Performance, Orthopedic Immobilization, Knee Brace. 


\section{Introduction}

The field of joint-preserving knee surgery includes many procedures that call for use of a postoperative knee brace over several weeks. ${ }^{1-3}$ Moreover, knee braces are used as a part of nonsurgical treatment (e.g., medial collateral ligament sprains) or as a treatment in patients who do not want to or cannot undergo a surgical procedure. Such patients usually ask their treating physician whether they are able to drive and whether the knee brace will impair driving performance.

These challenging questions are of great importance because patient mobility and independence are important for quality of life. Of the various factors that constitute driving performance, brake response time (BRT) is considered one of the most important factors responsible for driving safety. ${ }^{4}$ Very few experimental studies have looked at BRT during orthopaedic immobilization of the right lower limb. ${ }^{5,6}$ Tremblay et al. ${ }^{5}$ investigated BRT during immobilization of the right leg with an ankle orthosis and a walking cast. Only Waton et al. ${ }^{6}$ have studied immobilization of the knee. Waton et al. compared an above-the-knee cast, a below-the-knee cast, and one type of knee brace with varying range-of-motion (ROM) settings. Impaired BRT was found for the casts and for the knee brace in the fully locked setting. Waton et al. concluded that any type of knee brace impairs driving ability. However, the findings reported in their study do not seem to justify this conclusion. This is because the study did not verify prolonged BRT for all their brace settings and because it analyzed only a small number of the knee brace types commonly used.

Apart from the issue of braces, previous research has investigated the effects of different orthopaedic procedures on BRT., ${ }^{1,3,-15}$ For most orthopaedic procedures, a 1-week abstinence (after knee arthroscopy) ${ }^{2}$ to 8 -week abstinence (after total hip arthroplasty) ${ }^{7}$ has been considered appropriate before resuming driving. ${ }^{11-14}$

Department of Orthopaedic Surgery; Medical University of Innsbruck, Austria 
Given the lack of evidence in the current literature, it was the objective of the study to assess driving ability (BRT) with commonly used knee braces. We hypothesized that BRT would show statistically significant differences among several types of knee braces and an unrestricted control run.

Department of Orthopaedic Surgery; Medical University of Innsbruck, Austria 


\section{Methods}

The local university ethics committee approved the study protocol, and written informed consent was obtained from all subjects before participation.

A total of 64 healthy participants were enrolled in this study. They were recruited from among the investigators' acquaintances. We recruited $50 \%$ men and $50 \%$ women and tried to include subjects of all ages. To be included in the study, participants must have had a valid driver's license, used the right foot exclusively for accelerating and braking, and must have been free of any medical condition that could impair the ability to drive. Excluded were volunteers who were taking medications that could affect reaction time (e.g., benzodiazepines and over-the-counter allergy and cold medications) or had a history of alcohol or drug abuse, a central nervous system disorder such as epilepsy, a metabolic disorder, a psychiatric disorder, or musculoskeletal disease, as well as participants with any recent (previous 3 months) surgery on the right lower limb or any visual acuity disorder.

BRT measurements with an experimental apparatus were performed according to protocols of previous studies performed by our group and other researchers in the field (Fig 1). ${ }^{4,11,16}$ An adjustable car seat was fixed on a frame with hanging pedals mounted on rubber-damped pivots. The seat was adjusted to simulate the participant's customary driving position regarding seat inclination, headrest position, and seatpedal distance, as in previous research. ${ }^{17}$ An external case containing the logic gate electronics, a green lamp and a red lamp was positioned on a table at a constant distance in front of the frame. ${ }^{11}$ The experiment started when the accelerator was fully depressed and the green light lit up. After an interval of 5 to 30 seconds (at the investigator's discretion), the investigator (D.D.) pushed an external trigger concealed from the participant's view that switched the green light off and the red light on. This was the signal for the participant to activate the brake pedal as quickly as possible. The time interval (measured in

Department of Orthopaedic Surgery; Medical University of Innsbruck, Austria 
milliseconds) between the time when the red lamp was switched on and the time when the brake pedal was depressed was registered and denoted the BRT (Video 1, available at www.arthroscopyjournal.org). The above mentioned interval between tests was deemed not influenced by a fatigue effect. This is because we performed pilot tests earlier to determine whether 5 - to 10 -second intervals would lead to a fatigue effect over 40 repetitions. Such an effect was not found.

All tests were performed with the right foot, while the left foot rested on the coupling pedal. Each subject first performed 5 trial runs and walked a short distance to familiarize himself or herself with the brace before starting the experiment. BRT was measured 10 times for each knee brace model with an interval of 5 to 10 seconds between measurements. All volunteers were given the same standardized instructions. Moreover, each participant was asked to evaluate his or her own driving frequency according to the following responses: never, rarely, sometimes, often, and very often.

The right leg was assessed in 9 settings: without a knee brace (control group); with a typical postoperative knee brace with adjustable ROM (IROM; DonJoy, Vista, CA) set at $0^{\circ}$ to $30^{\circ}$, at $0^{\circ}$ to $60^{\circ}$, at $0^{\circ}$ to $90^{\circ}$, and at $20^{\circ}$ to $90^{\circ}$; with an unloader knee brace for patients with moderate to severe unicompartmental osteoarthritis (OA Adjuster; DonJoy); with a knee brace for patients with ligament instabilities (FullForce; DonJoy); with a knee brace for patients with patellofemoral disorders (Tru-Pull with Patellofemoral Sleeve; DonJoy); and with an elastic knee bandage (Genuforce; DonJoy SAS, Mouguerre, France). Fixation of knee braces was standardized and was always performed by the same investigator (D.D.). The order of the measuring sequence was randomized to counteract a possible learning effect (crossover design). This was performed using Randomizer, an Internet-based randomizer provided by the Institute for Medical Informatics, Statistics and Documentation at the Medical University of Graz (Graz, Austria; Available at https://www.meduniwien.ac.at/randomizer/web/login.php).

Statistical analysis of the impact of the various brace types on reaction time was performed with the help of a linear mixed model. For this analysis, reaction time was log\begin{tabular}{ll}
\hline PhD - Thesis & 9
\end{tabular} Department of Orthopaedic Surgery; Medical University of Innsbruck, Austria 
transformed to obtain normal distribution. The model included a fixed-effect "setting" with 9 levels (5 different orthoses with 8 different settings and 1 setting with no orthosis), a further term for the 10 repeated measurements per setting, and a random intercept at the participant level. Using post hoc pair-wise comparisons with Bonferroni correction, we compared each orthosis type and the setting with no orthosis. Driving frequency was constant throughout all conditions and did not require correction (adjustment). This is because we assessed the same participant sample at all time points (conditions). All analyses were performed with SPSS software, version 20.0 (SPSS, Chicago, IL). Power analysis was performed to compare the 9 settings regarding BRT. A sample of 64 participants with 9 assessments provides $80 \%$ power to detect an effect of $F=0.12$ $($ alpha $=.05$, sphericity correction $=0.8$, correlation between assessments $=0.50){ }^{18}$ Sphericity correction adjusts for the potentially unequal variances in the differences between all combinations of the groups. ${ }^{18}$ According to Cohen, ${ }^{18}$ this is a small effect. Power analysis was performed with $G^{*}$ Power, version 3.1.9 (Heinrich Heine University Düsseldorf, Düsseldorf, Germany)..$^{19,20}$ 


\section{Results}

The participants' sociodemographic characteristics and driving experience are presented in Table 1.

A total of 64 healthy volunteers (32 men and 32 women) were included in this study. The mean age was 33.5 years (SD, 13.1 years; range 18.2 to 70.8 years). The mean length of driving experience was 14.2 years (SD, 12.8 years; range, 0.5 to 50.7 years). The number of hours driven per week reported by our group was 5.2 (SD, 3.7). The participants reported an average distance traveled of 16,504 km/yr (SD, 15,076.8 km/yr; range, 100 to $62,000 \mathrm{~km} / \mathrm{yr}$ ). Driving frequency was subjectively rated as follows: very often $(n=18)$, often $(n=21)$, sometimes $(n=14)$, rarely $(n=5)$, and never $(n=6)$.

A significant difference was found between ROM of $0^{\circ}$ to $30^{\circ}(\mathrm{P}<.001)$, ROM of $0^{\circ}$ to $60^{\circ}(\mathrm{P}<.001)$, ROM of $0^{\circ}$ to $90^{\circ}(\mathrm{P}=.001)$, and $\mathrm{ROM}$ of $20^{\circ}$ to $90^{\circ}(\mathrm{P}=.005)$ compared with the control run. No significant difference in BRT was observed for the valgus brace for unicompartmental osteoarthritis, the knee brace for ligament instabilities, the patellofemoral brace, or the elastic knee bandage. No significant correlations were found between driving experience or distance traveled and BRT. The BRT for each test condition is shown in Table 2. All investigated knee braces are shown in Figure 2.

Department of Orthopaedic Surgery; Medical University of Innsbruck, Austria 


\section{Discussion}

The most important finding of our study was that BRT was significantly impaired with the postoperative knee brace at all assessed ROM settings. We therefore recommend caution in the use of a knee brace that restricts ROM. For example, the BRT difference between the IROM run with $\mathrm{ROM}$ of $0^{\circ}$ to $30^{\circ}$ and the control run was 79 milliseconds. This means an additional braking distance of $8.69 \mathrm{ft}(2.65 \mathrm{~m})$ at a driving speed of 75 $\mathrm{mph}(120 \mathrm{~km} / \mathrm{h})$.

No prolongation of BRT was observed for the typical patellofemoral realignment brace, ligament brace, valgus/osteoarthritis brace, or elastic knee bandage. However, allowing driving by any individual wearing these types of orthoses does not seem sufficiently safe. This is because the underlying specific knee pathology could further impair BRT, an aspect not covered by our study. Moreover, the ability to drive a car safely is multifactorial, and BRT is only one of several important factors that should be considered. Surgeons should take care when giving advice regarding driving a car with a knee brace. It might be speculated whether there is a specific amount of BRT increase that would lead to a higher accident likelihood. However, to our knowledge, there is no evidence to quantify the relation between BRT increase and accident risk. We performed a PubMed literature search and found no studies regarding the relation between impaired BRT, on the one hand, and accident risk, on the other hand. We therefore recommend that future studies be performed on this specific issue.

Our findings support and add to a previous work by Waton et al. ${ }^{6}$ that shows that increasing lower leg restriction is followed by a significant increase in reaction time. However, Waton et al. used only 1 knee brace and 4 different restriction settings, a below-the-knee plaster cast, and an above-the-knee plaster cast. They did not investigate the influence of additional restriction settings or other frequently used knee braces. Interestingly, they concluded that wearing a knee brace when driving is generally contraindicated. This is refuted by the findings of our study. Furthermore, it should be

Department of Orthopaedic Surgery; Medical University of Innsbruck, Austria 
mentioned that the study by Waton et al. involved only 23 participants, whereas our study comprised 64 healthy participants. Tremblay et al. ${ }^{5}$ found in their study that wearing a walking cast or a removable Aircast Walker (DJO) on the right lower limb increased emergency braking time during simulated driving. Nevertheless, despite this significant finding, their study does not prove that driving by healthy subjects with these types of immobilization of the right ankle involves a dangerously prolonged BRT because the observed variations in braking time and braking force were minimal. We agree with Waton et al. ${ }^{6}$ that in the study by Tremblay et al., ${ }^{5}$ the stimulus to brake came at random times between 3 and 5 seconds, thus creating a time window of only 2 seconds, which may indeed influence the participant's anticipation. In the study by Waton et al., the signal to brake appeared in a time window of 13 seconds. In our study the time window was 25 seconds, namely between 5 and 30 seconds from acceleration. Thus the participant's attention span was longer before the red light appeared.

BRT, as defined in our study, covers (1) neurologic reaction time, (2) foot transfer time, and (3) time necessary to generate pressure on the pedal. This is well in line with previous research in the field of driving safety. ${ }^{5,6,21}$ Reaction time is considered a complex task. ${ }^{22-24}$ It includes various psychomotor processes and is defined as the amount of time an individual takes to respond and complete a movement after a stimulus has been presented. ${ }^{22-24}$ In our study brake reaction time was defined as the amount of time it took for the participant to move his or her right foot from the accelerator to the brake pedal after the red light appeared on the driving simulator and did not distinguish among thinking time, movement time, and brake travel time as in the study by Waton et al. ${ }^{6}$

Our study is novel in that it is the first to test BRT in subjects wearing a broad range of common knee brace types. The main strengths of our study are the large number of participants; the standardized method; the randomized measuring sequence; and the fact that for each participant, 9 BRT measurements were performed with 5 different knee 
braces in 8 different settings and 1 measurement was performed with no brace, 10 times per setting.

The results of our study show that increasing the degree of restriction of the ROM of the right knee significantly increased BRT in our experimental emergency braking situation as compared with a situation in which the driver was unrestricted. We believe that our findings are of high clinical relevance because of the large number of knee pathologies requiring treatment with a knee brace, either as part of conservative, permanent treatment (e.g., osteoarthritis valgus/varus unloader brace) or in the postoperative setting after different surgical procedures (e.g., ligament reconstruction). 


\section{Limitations}

We acknowledge the following limitations of our study. Foremost, we did not investigate the combined effect of a specific knee pathology and a particular brace (e.g., patients with patellofemoral instability with or without a patellofemoral realignment brace). Instead, we analyzed the isolated effect of a knee brace in healthy subjects. We therefore cannot make a recommendation on patients with any kind of knee pathology or after knee surgery and the effect of wearing a knee brace on BRT. We also acknowledge the absence of BRT limits provided by the industry. This might weaken the clinical relevance of our findings. Moreover, categorized subjective driving frequency was used to quantify driving experience. The reliability and validity of driving ability with orthoses require further investigation.

In addition, it would have been beneficial to assess other orthotic treatments of the lower extremity such as hip or ankle orthoses. We believe that future studies should assess the influence of immobilization of the hip and ankle joint with various braces and increased restriction of movement to determine the impact of each joint on brake reaction time. Future studies should also include the combination of specific knee pathologies (anterior cruciate ligament, medial collateral ligament, and so on) and a knee brace. We also acknowledge as a possible limitation that we recruited our sample from our circle of acquaintances. 


\section{Conclusions}

Right-sided ROM-restricting knee braces involve significant impairment of BRT in healthy participants. No such prolonged BRT was found for a patellofemoral realignment brace, a ligament brace, a valgus/osteoarthritis brace, or an elastic knee bandage. However, our findings should be viewed in light of the limitations of the study, which are (1) the lack of a defined decrease in BRT that could lead to an accident and (2) uncertainty of whether the statistical differences are also clinically important. 


\section{Tables}

Table 1: Sociodemographic Characteristics and Driving Experience

$(\mathrm{N}=64 ;$ [32 Men 32 Women] )

\begin{tabular}{lrrr}
\hline & Mean & \multicolumn{1}{c}{ SD } & Range \\
\hline Age, yr & 33.5 & 13.1 & $18.2-70.8$ \\
Length of driving experience, yr & 14.2 & 12.8 & $0.6-50.7$ \\
Hours driven per week & 5.2 & 3.7 & $1.0-16.0$ \\
Distance traveled $\times 1,000 \mathrm{~km} / \mathrm{yr}$ & 16.5 & 15.1 & $0.1-62$ \\
\hline
\end{tabular}

SD (standard deviation) 
Table 2: Comparison of Assessed BRT for Each Test Setting

\begin{tabular}{|c|c|c|c|c|}
\hline \multirow[b]{2}{*}{ Type of Knee Brace } & \multicolumn{3}{|c|}{ BRT, ms } & \multirow{2}{*}{$\begin{array}{c}P \text { Value for } \\
\text { Comparison } \\
\text { With No Brace }\end{array}$} \\
\hline & Mean & $95 \% \mathrm{CI}$ & Impairment & \\
\hline No brace (control) & 594 & $573-615$ & $\mathrm{NA}$ & - \\
\hline \multicolumn{5}{|l|}{ IROM } \\
\hline ROM of $0^{\circ}$ to $30^{\circ}$ & 673 & $652-693$ & 79 & $<.001$ \\
\hline $\mathrm{ROM}$ of $0^{\circ}$ to $60^{\circ}$ & 629 & $611-647$ & 35 & $<.001$ \\
\hline ROM of $0^{\circ}$ to $90^{\circ}$ & 607 & $592-622$ & 13 & .001 \\
\hline ROM of $20^{\circ}$ to $90^{\circ}$ & 602 & $589-614$ & 8 & .005 \\
\hline FullForce & 601 & $584-618$ & 7 & .5 \\
\hline Tru-Pull & 587 & $573-602$ & NA & $>.99$ \\
\hline OA Adjuster & 585 & $571-598$ & NA & $>.99$ \\
\hline Elastic knee support & 589 & $574-604$ & NA & $>.99$ \\
\hline
\end{tabular}




\section{Figures}

Figure 1: Custom-made apparatus for measurement of brake response time. (A) Red light (visual stimulus initiating the braking procedure). (B) Green light (indicating that the accelerator is fully depressed; the subject is not in a ready-to-brake position). (1, coupler [clutch] pedal; 2, brake pedal; 3, accelerator pedal).

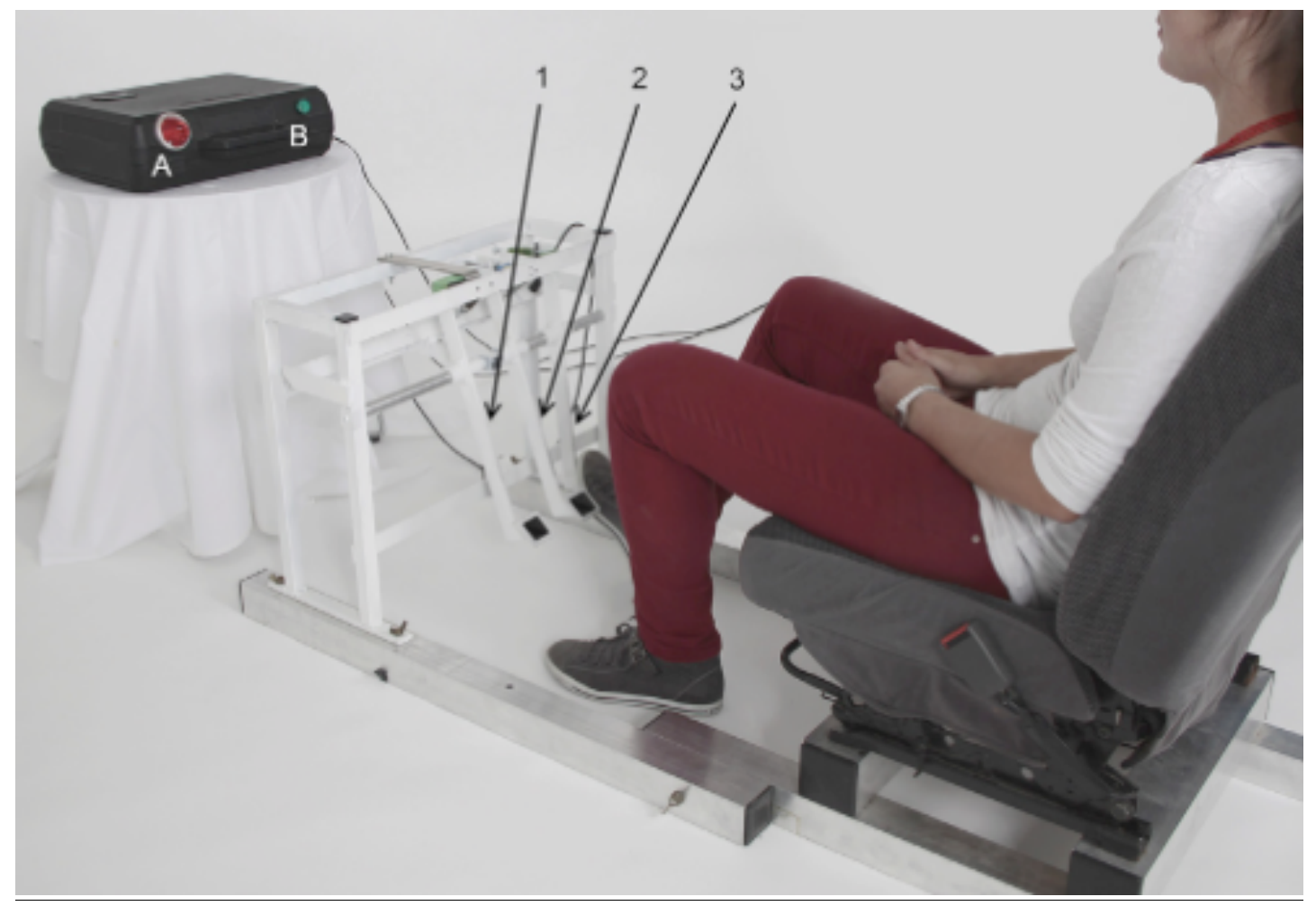

Department of Orthopaedic Surgery; Medical University of Innsbruck, Austria 
Figure 2: Investigated knee braces. (A) Knee brace for patients with moderate to severe unicompartmental osteoarthritis (OA Adjuster). (B) Knee brace for patients with ligament instabilities (FullForce). (C) Postoperative knee brace with adjustable range of motion (IROM). (D) Knee brace for patients with patellofemoral disorders (TruPull with Patellofemoral Sleeve). (E) Elastic knee bandage (Genuforce).

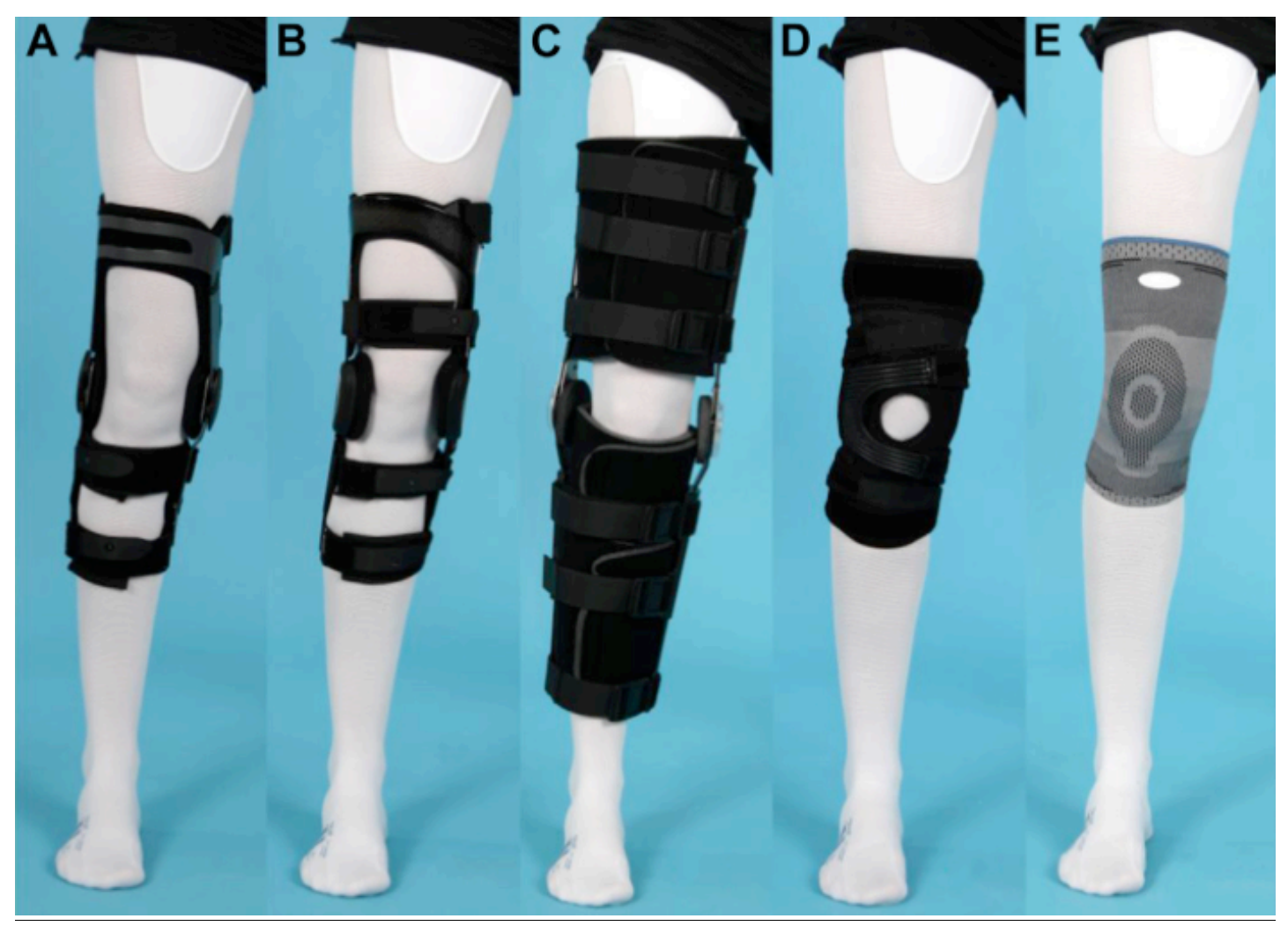




\section{Competing interests}

No benefit in any form has been received or will be received from a commercial party related directly or indirectly to the subject of this article. 


\section{References}

1. Gotlin RS, Sherman AL, Sierra N, Kelly M, Scott WN. Measurement of brake response time after right anterior cruciate ligament reconstruction. Arthroscopy 2000;16:151-155.

2. Hau R, Csongvay S, Bartlett J. Driving reaction time after right knee arthroscopy. Knee Surg Sports Traumatol Arthrosc. 2000;8:89-92.

3. Nguyen T, Hau R, Bartlett J. Driving reaction time before and after anterior cruciate ligament reconstruction. Knee Surg Sports Traumatol Arthrosc. 2000;8:226-230.

4. Al-khayer A, Schueler A, Kruszewski G, Armstrong G, Grevitt MP. Driver reaction time before and after treatment for lumbar radiculopathy. Spine 2008;33:1696-1700.

5. Tremblay MA, Corriveau H, Boissy $\mathrm{P}$, et al. Effects of orthopaedic immobilization of the right lower limb on driving performance: An experimental study during simulated driving by healthy volunteers. J Bone Joint Surg Am 2009;91:2860-2866.

6. Waton A, Kakwani R, Cooke NJ, et al. Immobilisation of the knee and ankle and its impact on drivers' braking times. A driving simulator study. J Bone Joint Surg $\mathrm{Br}$ 2011;93:928-931.

7. Macdonald W, Owen JW. The effect of total hip replacement on driving reactions. J Bone Joint Surg Br 1988;70:202-205.

Department of Orthopaedic Surgery; Medical University of Innsbruck, Austria 
8. Pierson JL, Earles DR, Wood K. Brake response time after total knee arthroplasty When is it safe for patients to drive? J Arthroplasty 2003;18:840-843.

9. Gotlin RS, Sherman AL, Sierra N, Kelly MA, Pappas Z, Scott WN. Measurement of brake response time after right anterior cruciate ligament reconstruction. Arch Phys Med Rehabil 2000;81:201-204.

10. Spalding TJ, Kiss J, Kyberd P, Turnersmith A, Simpson AH. Driver reaction-times after total knee replacement. J Bone Joint Surg Br 1994;76:754-756.

11. Liebensteiner MC, Birkfellner F, Thaler M, Haid C, Bach C, Krismer M. Driving reaction time before and after primary fusion of the lumbar spine. Spine 2010;35: 330-335.

12. Liebensteiner MC, Kern M, Haid C, Kobel C, Niederseer D, Krismer M. Brake response time before and after total knee arthroplasty: A prospective cohort study. BMC Musculoskelet Dis 2010;11:267.

13. Lechner R, Thaler M, Krismer M, Haid C, Obernauer J, Obwegeser A. Driving reaction time before and after anterior cervical fusion for disc herniation: A preliminary study. Eur Spine J 2013;22:1517-1521.

14. Thaler $M$, Lechner $R$, Foedinger $B$, et al. Driving reaction time before and after surgery for lumbar disc herniation in patients with radiculopathy. Eur Spine $\mathrm{J}$ 2012;21:2259-2264.

15. Dalury DF, Tucker KK, Kelley TC. When can I drive? Brake response times after contemporary total knee arthroplasty. Clin Orthop Relat Res 2011;469:82-86.

Department of Orthopaedic Surgery; Medical University of Innsbruck, Austria 
16. Ganz SB, Levin AZ, Peterson MG, Ranawat CS. Improvement in driving reaction time after total hip arthroplasty. Clin Orthop Relat Res 2003:192-200.

17. Scott PA, Candler PD, Li JC. Stature and seat position as factors affecting fractionated response time in motor vehicle drivers. Appl Ergon 1996;27:411-416.

18. Cohen J. Statistical power analysis for the behavioral sciences, Ed 2. Hillsdale, NJ: L. Erlbaum Associates, 1988.

19. Faul F, Erdfelder E, Lang A-G, Buchner A. G*Power 3: A flexible statistical power analysis program for the social, behavioral, and biomedical sciences. Behavior Research Methods 2007;39:175-191.

20. Faul F, Erdfelder E, Buchner A, Lang A-G. Statistical power analyses using G*Power 3.1: Tests for correlation and regression analyses. Behavior Research Methods 2009;41:1149-1160.

21. Holt G, Kay M, McGrory R, Kumar CS. Emergency brake response time after first metatarsal osteotomy. J Bone Joint Surg Am 2008;90:1660-1664.

22. Morrison RW, Swope JG, Halcomb CG. Movement time and brake pedal placement. Hum Factors 1986;28:241-246.

23. Retchin SM, Cox J, Fox M, Irwin L. Performance-based measurements among elderly drivers and nondrivers. J Am Geriatr Soc 1988;36:813-819.

Department of Orthopaedic Surgery; Medical University of Innsbruck, Austria 
24. Spirduso WW. Reaction and movement time as a function of age and physicalactivity level. J Gerontol 1975;30:435-440. 


\section{Acknowledgment}

First and foremost, I would like to express my special appreciation and thanks to my supervisor Priv. Doz. Mag. Dr. Michael Liebensteiner, PhD for his understanding advice and support during the whole $\mathrm{PhD}$ project. Michael has also reviewed the thesis in terms of form and content as well as helped me a lot for writing the manuscript. Without his support my PhD project would never have been realized.

Second, I want to thank Prof. Dr. Martin Krismer, $1^{\text {st }}$ committee member and chairman of our department. I will never forget his sincerity and encouragement.

Third, I am also indebted to Priv. Doz. Dr. Rainer Biedermann, it was him who came up with the idea to apply for a PhD position. It seems like forever ago when I met him during my medical studies and I feel privileged to have the opportunity to work with him.

Moreover I am truly grateful to Christian Haid for his support as the study coordinator and for designing and developing the test apparatus.

I also acknowledge Hannes Riedigier, Carmen Unteregger, and Constanze Stampfer for photographing the custom-made apparatus for measurement of brake response time and the knee braces.

Last but by no means least, I would like to thank my family for always believing in me and for all their love and support. They have encouraged and helped me in innumerable ways throughout my life.

Department of Orthopaedic Surgery; Medical University of Innsbruck, Austria 
13. Appendix

13.1. Case Report Form

है
|

อ

ปั

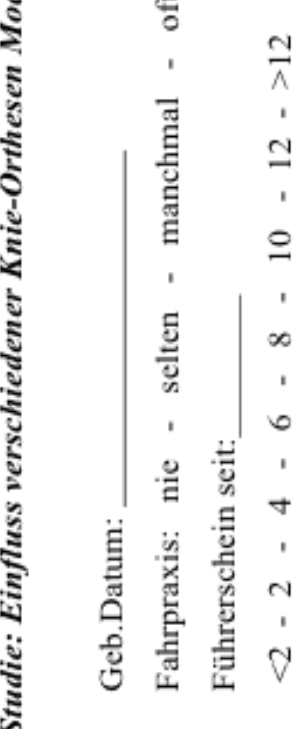

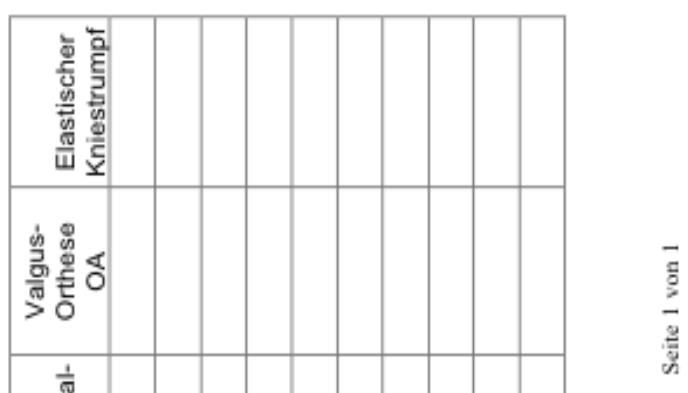



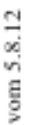

吾 


\subsection{Ethics committee approval}

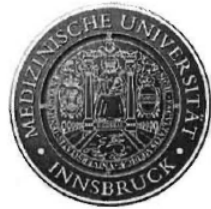

Ełhikkommission der Medizinischen Universität Innsbruck

\section{Geschäftsstelle}

Innrain 43 / 1. Stock

Tel.:+43-512-504-25444 od. -22293

A-6020 Innsbruck

Fax:+43-512-504-22295

Email: Ethikkommission@i-med.ac.at

Studienkennzahl: UN4808 Sitzungsnummer: $316 / 4.12$

Herrn

Mag. Dr. M. Liebensteiner

Univ.-Klinik für Orthopädie

Anichstraße 35

6020 Innsbruck

Innsbruck, 21.09.2012/AA

Betrifft: Mag. Dr. M. Liebensteiner, Univ.-Klinik für Orthopädie

Einfluss verschiedener Knie-Orthesen Modelle auf die Bremsreaktionszeit

Sponsor: AS

Bezelchnung
EKI-Antragsformular:
ICF:
Protokoll:
CRF:
Versicherung:
Anschreiben:
CV:

Version

01.08 .12

Version 1, 1.8.12(Proband):

Version 1, 1.8.12

Version 1, 5.8.12

wn

01.08 .12

CV:

31.07 .2012

Sehr geehrter Herr Dr. Liebensteiner!

Die og Studie wurde in der 316. Sitzung am 30.08.12 behandelt. Nach Erhalt

- des überarbeiteten EK1-Antragformulars, 19.09.12 (erh. 20.09.12)

- der Versicherungsbestätigung, Pol.Nr. 07208763-1, 18.09.12 (erh. 18.09.12)

- der überarbeiteten Patienteninformation und Einverständniserklärung, Version 2, Sept. 12 (erh. 18.09.12)

wird die Studie hiermit für die Durchführung in Innsbruck unbedenklich erklärt.

\section{Mit besten Grüßen}

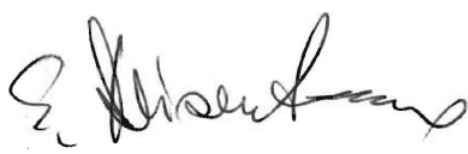

Ao. Univ.- Prof. Dr. E. Deisenhammer

(2. Stv.- Vorsitzender)

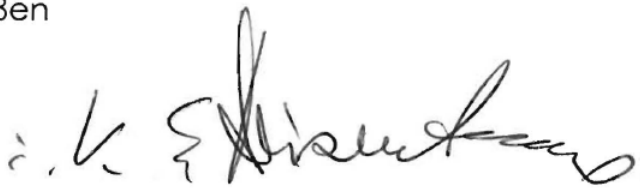

Univ.- Prof. DI Dr. P. Lukas

(Vorsitzender)

Department of Orthopaedic Surgery; Medical University of Innsbruck, Austria 


\subsection{AGES committee approval}

\section{Bundesamt für Sicherheit im Gesundheitswesen}

AASG / AGES

Institut Inspekticnen, Medizinprodukte \& Hämovigilane Traisengasse 5, A-1200 Wien

INS-621000-0465-004
Universitătsklinik für Orthopädie Innsbruck Univ, Prof. Dr. Martin Krismer Anichstraße 35 A-6020 Innsbruck

$\begin{array}{ll}\text { Datum: } & \text { 15. Mai } 2013 \\ \text { Kontakt: } & \text { Dr, med. Violetta Zmuda } \\ \text { Telefon: } & +43(0) 50555-36441, \text { Fax: }-36409 \\ \text { E-Mail: } & \text { inspektionenglages.at }\end{array}$

\section{Bestätigung der ordnungsgemäßen Erstmeldung einer klinischen Prüfung eines Medizinproduktes gemăß § $\mathbf{4 0}$ Abs. 3 MPG}

Sehr geehrter Herr Prof. Krismer, sehr geehrter Herr Dr. Liebensteiner,

das Bundesamt für Sicherheit im Gesundheitswesen bestätigt hiermit die formale Vollständigkeit der klinischen Prüfung „Einfluss verschiedener Knie-Orthesen Modelle auf die Bremsreaktionszeit (1.8.2012)" mit Datum 15. Mai 2013.

Gemäß § 40 Abs. 3 kann mit der klinischen Prüfung begonnen werden.

Die klinische Prüfung wird unter der Referenznummer INS-621000-0465 geführt. Dieser Code ist bei allen weiteren Schriftstücken im Rahmen des Schriftverkehrs zu dieser Studie als Referenz anzuführen.

Alle schwerwiegenden unerwünschten Ereignisse sind entsprechend § 42 Abs. 8 MPG idgF vom Sponsor vollstăndig zu registrieren und unverzüglich dem Bundesamt für Sicherheit im Gesundheitswesen und den zuständigen Behörden der anderen betroffenen Vertragsparteien des EWR, in denen die klinische Prüfung durchgeführt wird, zu melden.

Zusätzlich sind die Meldepflichten gemäß § 70 MPG idgF zu beachten.

Weiters wird aufgefordert dem Bundesamt für Sicherheit im Gesundheitswesen alle bedeutsamen Änderung am Prüfplan, die sich insbesondere auf die Sicherheit der Prüfungsteilnehmer auswirken oder die wissenschaftliche Aussagekraft der klinischen Prüfung beeinflussen können, gemăß §̧ 40a MPG idgF an das BASG zu übermitteln.

Darüber hinaus sind Änderungen an der Patienteninformation und am Handbuch des klinischen Prüfers sowie eine Beendigungsmeldung und ein Abschlussbericht dieser klinischen Studie an das BASG zu übermitteln.

Meldungen bzw. sonstige Korrespondenz zur klinischen Prüfung sind schriftlich an das Bundesamt für Sicherheit im Gesundheitswesen, Institut Inspektionen,

Bundesamt für Sicherheit im Gesundheitswesen 
Medizinprodukte \& Hämovigilanz, Traisengasse 5, 1200 Wien, Austria oder an die offizielle Institutsadresse inspektionen@ages.at zu richten.

Wichtige Informationen und alle Formulare sind auf folgender Website zu finden: http://www.basg.at/medizinprodukte/klinische-pruefung/.

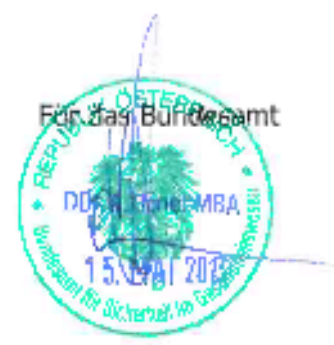

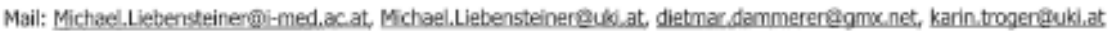




\subsection{Abstracts and Publication}

Original research publication authored by the candidate on work relating to this thesis

Effect of Knee Brace Type on Braking Response Time During Automobile Driving

Dammerer D, Giesinger JM, Biedermann R, Haid C, Krismer M, Liebensteiner M „Arthroscopy - The Journal of Arthroscopic and Related Surgery“ Vol 31, No 3 (March), 2015: $p p$ 404-409

\section{List of abstracts of presentations}

Oral - Presentation

Driving ability with a knee brace depends on the type of brace

Liebensteiner M., Dammerer D., Giesinger J., Biedermann R., Haid C., Krismer M. 16th ESSKA (European Society of Sports Traumatology, Knee Surgery \& Arthroscopy); Congress Amsterdam, 2014

\section{Poster-Presentation}

Driving Ability with a Knee Brace Depends on the Type of Brace

D. Dammerer, J. Giesinger, R. Biederman, C. Haid, M. Krismer, MC. Liebensteiner, 9th Meeting of PhD Students of Innsbruck Universities; Innsbruck, 2013

Department of Orthopaedic Surgery; Medical University of Innsbruck, Austria 


\subsection{Poster Presentation}

$9^{\text {th }}$ Meeting of PhD Students of Innsbruck Universities; 2013, Innsbruck, Austria

\section{Driving ability with a knee brace depends on the type of brace.}

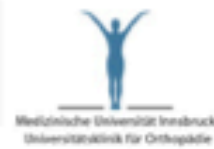

Dammerer $\mathrm{D}^{\mathrm{a} ;}$, Giesinger $\mathrm{J}^{\mathrm{b}}$, Biedermann $\mathbf{R}^{\mathrm{a}}$, Haid $\mathrm{C}^{\mathrm{a}}$, Krismer $\mathbf{M}^{\mathrm{a}}$, Liebensteiner $\mathrm{MC}^{\mathrm{a}}$

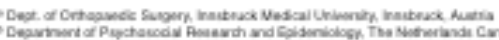

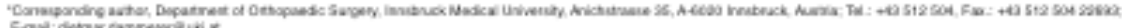

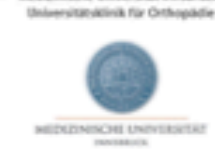

\section{BACKGROUND}

- Patients wish to know if they are able to drive a car safely wearing certain knee braces

- Brake response time (BRT) is one of the most important factors responsible for driving safety ${ }^{1.2}$

- Several studies on BRT in the context of orthopaedic procedures (THA, spinal fusion, TKA, ACL reconstruction...) are published but to our knowledge very few studies are investigating the effect of orthopaedic immobilization of the right lower limb on the driving performance and those studies are providing irreproducible conclusion ${ }^{3.4}$

\section{ABSTRACI}

Background: The question whether or not a pasent with a knee brace shou drive a car is of abwous importanoo. Previous studes on tis specitic bse. are rave and provised non reproducibie conclusions. Brake response time (BAT) is oonsibered one of the most important factors for driving safety

Methods: Staty-four healthy participars (32 femais, 32 male) participated in our shudy. Wo assessed BRT for flwe different commonly used knoe braoes used in nine ditterent groupl wath a typical postoperasve knoes grace with aquetable range of motion and the settings $0^{\circ}$ to $30^{\circ}, 0^{\circ}+060^{\circ}, 0^{\circ}+0$

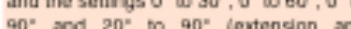
$90^{\circ}$ and $20^{\circ}$ to $90^{\circ}$ (eutensian and flewiony, as wel as with an unicadro unkompartmortal coscourtrits, brace for patolotomoral disorders and an clastic knoo bandage. BRT was simulater.

Results: The 64 participants (moan age 33.5 years) showed signicartt impaired BAT with the typical postoperative brace set at AOM $0^{\circ}$ io $30^{\circ}$

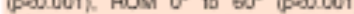
FOM $0^{\prime \prime}$ is $90^{\circ}$ ( $\mathrm{pm}=0.001$ ) and ROM $20^{\circ}$ to $90^{\circ}[\mathrm{p}=0.005]$ as compared to the control group. However, no such Impaired BRT was found for any other imestigatod knee brace.

Conclusions: ROM-resticting kneo braces appear to irwolve signincartly impaired BRT. No such prolonged BRT impas tound for the patel ofemoral realignment brame the ligament brace, the valgus/OA brade or the elastic knoe the valgusiOA brade or the elastic knse
bandage. Therefore, wo recommend driving abstinence only for subjects driving abstinenoe only for subjocts wearing a knoe tra

Clinical Relevance: The study providas information on driving ability with very comman and trequertily uset knos braces.
METHODS

\section{Participants:}

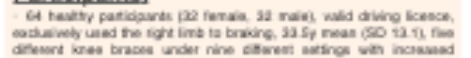

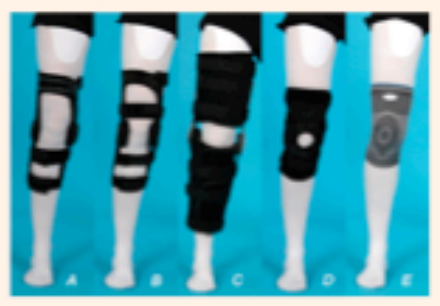

Precedures:
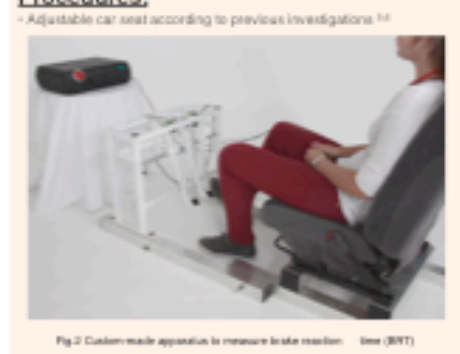

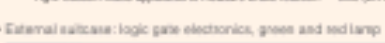

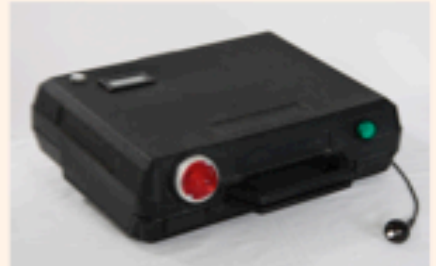

natumes ats

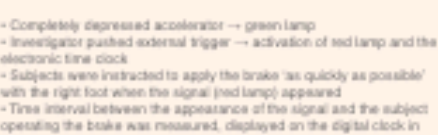

RESULTS

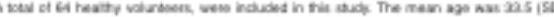

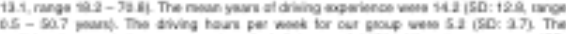

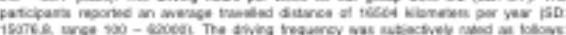

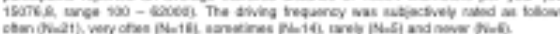

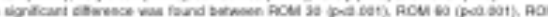

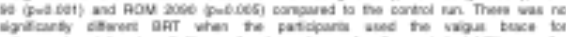

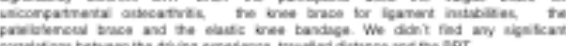

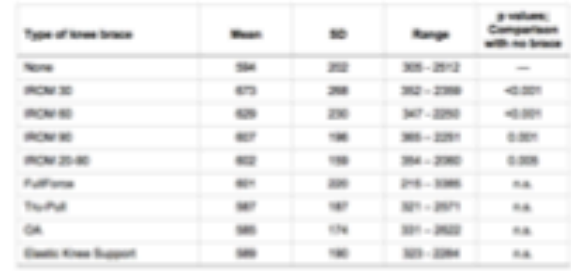

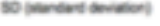

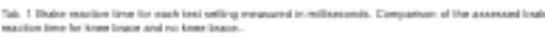

\section{DISCUSSION \& CONCLUSION}

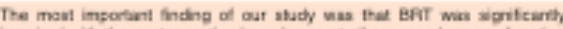

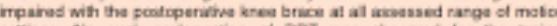

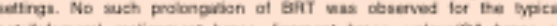

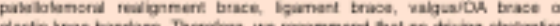

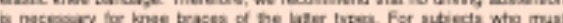

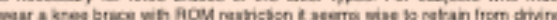
a car.

We regard out susy as vey rekwart, becmuse in the feld of joint.

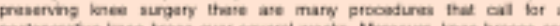

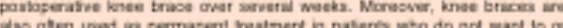
Co

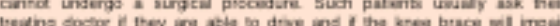
diving pertsemanse. This chelenging quetion is of greal importanse,

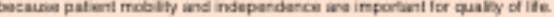

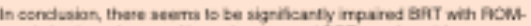

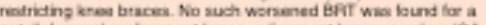

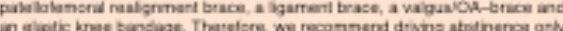

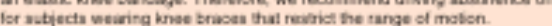

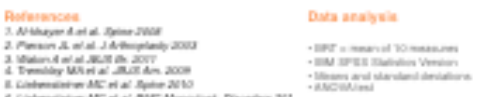

Department of Orthopaedic Surgery; Medical University of Innsbruck, Austria 


\subsection{Further scientific work}

\subsubsection{Original - Research publications}

- D. Dammerer, K. Kirschbichler, L.Donnan, G. Kaufmann, M. Krismer, Biedermann R.

Clinical value of the Taylor Spatial Frame: a comparison with the Ilizarov and Orthofix fixators.

Journal of Children's Orthopaedics, 2011, Volume 5, Number 5, Pages 343-349

- Braito M, Liebensteiner M, Dammerer D, Krismer M, Pfurner M, Biedermann R. Poor accuracy of plain radiographic measurements of prosthetic migration and alignment in total ankle replacement.

J Orthop Surg Res. 2015 May 20;10(1):71. doi: 10.1186/s13018-015-0220-x.

- Braito M., Dammerer D., Reinthaler A., Kaufmann G., Huber D., Biedermann R. Effect of Coronal and Sagittal Alignment on Outcome After Mobile-Bearing Total Ankle Replacement

Foot Ankle Int. 2015 Apr 21. pii: 1071100715583383. [Epub ahead of print]

- Braito M., Dammerer D., Kaufmann G., Fischler S., Carollo J., Reinthaler A., Huber D., Biedermann R.

Are our expecations bigger than the results we achieve? A comparative study analysing potential advantages of ankle arthroplasty over arthrodesis. Int Orthop. 2014 Aug;38(8):1647-53. doi: 10.1007/s00264-014-2428-5. Epub 2014 Jul 2.

Department of Orthopaedic Surgery; Medical University of Innsbruck, Austria 


\subsubsection{Abstracts - Oral Presentations}

- Driving ability is impaired within certain orthotic ankle devices

Dammerer D., Waidmann C., Huber D., Haid C., Krismer M., Liebensteiner M. 10th international Meeting of the Austrian Foot Society, 2014

- Longterm results of joint preserving hallux valgus surgery in 1200 cases.

Kaufmann G., Sinz S., Dammerer D., Biedermann R.

10th International Meeting of the Austrian Foot Society, 2014

- Endoprothese oder Arthrodese des Sprunggelenks? Ein Vergleich klinischer, radiologischer und ganganalytischer Ergebnisse.

Biedermann R., Braito M. Dammerer D., Reinthaler A., Kaufmann G.

31. Jahrestagung der Österr. Gesellschaft für Orthopädie und orthopäd. Chirurgie, 2013

Department of Orthopaedic Surgery; Medical University of Innsbruck, Austria 


\subsubsection{Poster - Presentation}

$16^{\text {th }}$ ESSKA (European Society of Sports Traumatology, Knee Surgery \& Arthroscopy) Congress Amsterdam, 2014
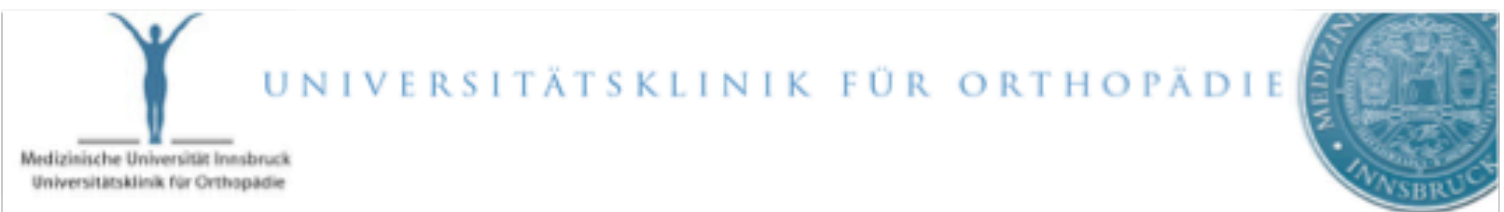

\section{Driving ability is impaired with certain orthotic ankle devices}

Dammerer D. ${ }^{1}$, Waidmann C., Huber D. ${ }^{2}$, Thaler M. ${ }^{1}$, Krismer M. ${ }^{1}$, Liebensteiner MC. ${ }^{1}$,

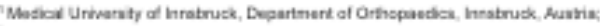

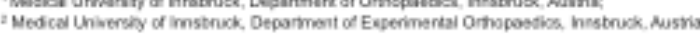

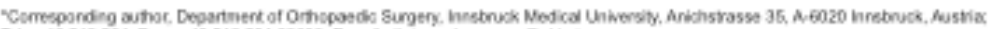

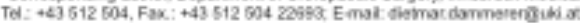

\section{Background:}

Patients wearing orthotic devices on the right lower limb often seek advice from their treating doctor as to whether or not they are able to drive a car. This chalenging question if a patient with an ankle brace should be allowed to drive a car is of obvious importance. Previous studies on that specific issue are rare and provided irreproducible conclusions. The brake response time (BRT) is considered as one of the most important factors for driving safety. It was the purpose of the study to evaluate the influence of typical ankle braces on driving ability. We hypothesized that there would be significant differences in the major parameter of driving safety (BRT, brake response time) between the investigated ankle braces and a non-restricted control run.

\section{Methods:}

Applying a prospective design 70 healthy participants (35 Men, 35 Women) participated in our study. BRT was assessed under the following six conditions: without a brace (control) (1), with a typical postoperative ankle brace with adjustable range of motion and the settings: unrestricted (2), fixed at $15^{\circ}$ (3) plantarflexion, restricted with $0^{*} / 15^{*} / 45^{*}$ (4) (dorsiplantarflexion, respectively), a brace for ligament instabilities (5) and an elastic ankle bandage (6). The BRT was assessed using a custom-made driving simulator. Participants were instructed to apply the brake exclusively with the right foot as quickly as possible on a visual stimulus. The time interval umil the subject operated the brake was measured 10 times, averaged and then taken as BRT value

\section{Results:}

The 70 participants (mean age 31.1 years) showed significantly impaired BRT with the postoperative brace setting of unrestricted ROM (p<0.001), ROM fixed at $15^{\circ}$ plantarflexion (p<0.001) and ROM $0^{*} / 15^{*} / 45^{*}$ dorsi- $/$ plantarllexion (p<0.001) compared to the control group. However, no such impaired BRT was found for all other investigated ankle braces.

Conclusions:

There seems to be significantly impaired BRT with ROMrestricting ankle braces. No such worsened BRT was found for an elastic ankle bandage or a ligament brace.

We therefore recommend a strict driving abstinence for amy subjects wearing an ankle brace that restricts range of motion. However, it does not seem safe enough to allow driving to all individuals that wear ankle orthoses of the latter kinds. This is because an underlying specific ankle pathology could further impair BRT - an an which was not covered by the study at hand and should be adressed by future investigations.

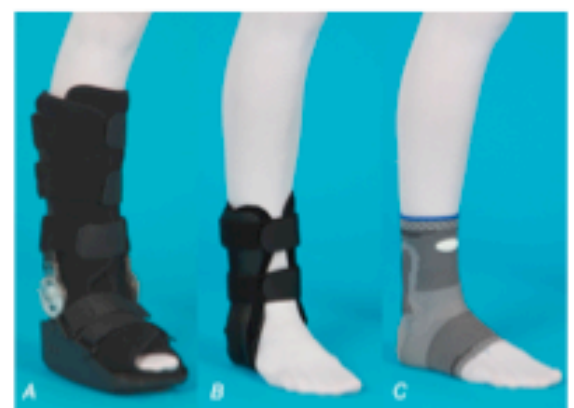

Figure 1: Investigated ankle braces.

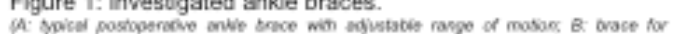

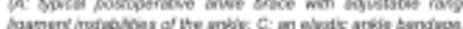

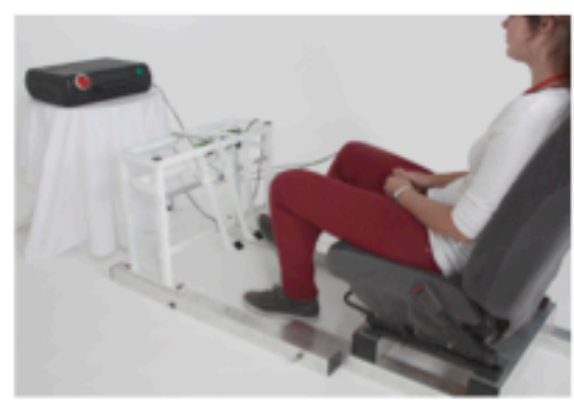

Figure 2: Custom-made apparatus to measure brake reaction time (BRT). BRT was measured in Milliseconds.

\begin{tabular}{|c|c|c|c|c|}
\hline Type of insee bracos & man & 50 & Punon & $\lim _{n \rightarrow \infty}$ \\
\hline 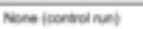 & $\operatorname{sen} 2$ & 209 & $200-2002$ & - \\
\hline Maxtrax uneuredied & 672 & $m$ & $200-2001$ & gesent \\
\hline Maxtras isis & $\operatorname{css}$ & 2004 & $2 m-300$ & staven \\
\hline Mactras sow & $\operatorname{mos}$ & 100 & $201-200 y$ &, $0400 \mathrm{n}$ \\
\hline Notedore & $\operatorname{ses} 4$ & sest & 2ae - noe & rasn \\
\hline nowere stround & $s m_{3}$ & 190 & $20 y-x=4$ & geant \\
\hline
\end{tabular}

Table 2: Brake reaction time measured in msec. with the different orthoses - compared to the control run. SD (Standard Deviation)

Clinical Relevance: The study provides information on driving ability with very common and frequently used knee braces. 
- The effect of ankle brace type on braking response time - a randomized study.

Dammerer D. ${ }^{1}$, Waidmann C. ${ }^{1}$, Huber D. ${ }^{2}$, Thaler M. ${ }^{1}$, Krismer M. ${ }^{1}$, Liebensteiner MC. ${ }^{1}$

${ }^{1}$ Medical University of Innsbruck, Department of Orthopaedics, Innsbruck, Austria;

${ }^{2}$ Medical University of Innsbruck, Department of Experimental Orthopaedics, Innsbruck, Austria

- Effect of hip braces on brake response time - a randomized controlled study

Dammerer D. ${ }^{1}$, Waidmann C. ${ }^{1}$, Braito M. ${ }^{1}$, Haid C. ${ }^{1}$, Krismer M. ${ }^{1}$, Liebensteiner MC. ${ }^{1}$

${ }^{1}$ Medical University of Innsbruck, Department of Orthopaedics, Innsbruck, Austria

- Effect of Surgical Shoes on The Brake Response Time After First Metatarsal Osteotomy

Dammerer D. ${ }^{1}$, Braito M. ${ }^{1}$, Biedermann R. ${ }^{1}$, Ban M..${ }^{1}$, Giesinger J. ${ }^{2}$, Kaufmann G. ${ }^{1}$,

${ }^{1}$ Medical University of Innsbruck, Department of Orthopaedics, Innsbruck, Austria

2 Medical University of Innsbruck, Department of Psychiatry and Psychotherapy, Innsbruck, Austria 


\section{Declaration of Originality}

I hereby declare that this thesis and the work reported herein was composed by and originated entirely from me. Information derived from the published and unpublished work of others has been acknowledged in the text and references are given in the list of sources.

Innsbruck, June 2015

Dietmar Dammerer, MD 
The original article (Pages 38 - 43) has been removed for online access of this thesis.

"Effect of Knee Brace Type on Braking Response Time During Automobile Driving"

In: Arthroscopy: The Journal of Arthroscopic \& Related Surgery, Volume 31, Issue 3, March 2015, Pages 404-409

doi:10.1016/i.arthro.2014.09.003

http://www.sciencedirect.com/science/article/pii/S0749806314007750 